\title{
Collaborative Collection Management in a High-density Storage Facility
}

\section{Scott Seaman}

This case study reviews selected collection management issues encountered in a collaboratively managed high-density remote storage facility. In 2000, four Colorado institutions - the University of Colorado at Boulder, the University of Colorado at Denver, the University of Colorado Health Sciences Center, and the University of Denver-opened a shared highdensity storage facility. This mix of public and private institutions agreed to collaborative collection management, including a nonduplication policy and the granting of direct access to stored materials for nonparticipating institutions through a statewide union catalog. Ownership of stored materials, selection of items for storage, operational management, and online and physical access proved to be challenging policy issues requiring committees, patience, and compromise to resolve.

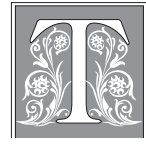

he Association of Research Libraries (ARL) estimates that member libraries added $9,480,045$ volumes to their collections in 2001-2002. ${ }^{1}$ Given a conservative estimate, one would expect such magnitude of materials to occupy $1,185,000$ linear feet of shelving space or 225 miles of shelves annually. Yet, even among those universities that undertook library construction projects during the 1990s, few added significant shelf space on which to store the growing print collections. Instead, today's library planners and architects choose to reduce footprints of traditional shelving in order to open vast areas of library floor space for collaborative study space and information technology. ${ }^{2}$ To accommodate this shift, millions of seldom-used volumes are being systemati- cally removed from library shelves each year for permanent storage in off-campus facilities. Since the late 1990s, in fact, leading library architects and planners have assumed that any library with more than a million volumes would maintain an offcampus storage facility as an integral part of its collection management strategy. ${ }^{3}$

Although libraries have adopted many different models for off-campus book storage (at least within the ARL), highdensity storage facilities are becoming the preferred choice, with more than two dozen opening in the past fifteen years. ${ }^{4}$ High-density facilities store volumes arranged by size on unusually tall shelving rather than sequentially by call number in traditional library stacks. By storing materials by size rather than call number, space efficiencies of more than

Scott Seaman is Associate Director for Administrative Services in Norlin Library at the University of Colorado at Boulder; e-mail: Scott.Seaman@Colorado.edu. 
seven times are realized when compared to traditional shelving. This significantly reduces land, construction, and operating costs. High-density storage facilities also can provide state-of-the-art preservation environments for materials. An online catalog record for each item informs patrons that the item is stored in a remote location, and items are typically requested by the patron directly through the online catalog. Regular courier deliveries bring requested materials to campus. ${ }^{5}$

\section{PASCAL Partnership}

Colorado's high-density facility, the Preservation and Access Service Center for Colorado Academic Libraries (PASCAL), is jointly operated by four libraries: the University of Colorado at Boulder, the University of Colorado at Denver, the University of Colorado Health Sciences Center, and the University of Denver. PASCAL is not only one of the earliest collaborative high-density storage facilities, but it is unique in that it forms a public-private partnership between the campuses of the University of Colorado at Boulder, at Denver, and the Health Sciences Center, all public institutions, and the University of Denver, a private institution.

In their 2002 review of the literature, Steve O'Connor, Andrew Wells, and Mel Collier noted that "collaborative storage implies a shared approach to collection in terms of growth, shape, management and access." ${ }^{\prime \prime}$ Throughout the planning process, PASCAL was envisioned as a collaboratively managed facility that integrated diverse collections, offered electronic access to its contents, and provided rapid delivery to the participating partners and, equally important, to the wider Colorado library community. Each library brought unique collections and user demands to the partnership, but it also was recognized that such a collaborative facility could contribute to a shared storage solution and could offer unique services for the benefit of a much larger community.

Although several high-density storage facilities, including the University of California's Southern Regional Library Facility, the University of Missouri Libraries Depository, and the Southwest Ohio Regional Depository, cooperate to share a common facility, none of those facilities manages stored collections collaboratively. In the literature, only the Five-College Library Depository in Massachusetts reports deaccessioning duplicate copies with joint ownership of the stored collection. ${ }^{7}$ PASCAL proved more far reaching than all of these facilities by committing to collaborative collection management and by offering collection access and delivery to a large number of nondepositing libraries. By doing so, it has become a statewide resource for both academic and public libraries.

Four institutions jointly proposing an inexpensive solution to a persistent library shelving problem proved a compelling project for the conservative Colorado legislature to fund. At the same time, implementing common policies and operational processes proved challenging for the four libraries. The mission of each institution, and therefore of each library collection, was very different. Boulder represented an ARL library supporting Ph.D. programs in forty-four fields. In the mid-1990s, the Boulder campus enrolled 22,000 FTE students and had a library collection of more than three million volumes. The Health Sciences Center's Dennison Library supported the state's only medical school and a nationally recognized biomedical research program. In the mid-1990s, the Health Sciences Center enrolled 2,600 FTE students and had a library collection of 265,000 volumes, and the Auraria campus enrolled 23,000 FTE students with a library collection of 600,000 volumes. The University of 
Denver, the oldest private university in the Rocky Mountain region, enrolled approximately 9,500 students in the mid1990s and its Penrose Library held more than a million volumes.

That such a diverse set of institutions would partner on a high-density storage facility is largely the result of pragmatism and geography. By the mid-1990s, all four libraries needed additional space and all four were located in the Denver metropolitan area. Each library cited examples of how shelving had been added to its buildings, thus eliminating ever-greater amounts of student seating. All four institutions were experiencing the impact of changing classroom teaching practices that necessitated more group and collaborative study spaces in libraries. With increasing pressures for group study space, the libraries were unable to meet the student demand. The Auraria Library, in fact, was not at capacity for materials. Instead, it cited the need for modern student seating as the primary reason for moving low-use materials to high-density storage. ${ }^{8}$

Regardless of whether the primary reason was to create shelf space for new materials or to open additional seating space for students, none of the four institutions was able to construct additional on-campus library space. Boulder had gone so far as to lease traditional warehouse space off-campus, but that was proving to be an inefficient use of funds. ${ }^{9}$ Whether the constraint was lack of funds, insufficient land, or campus administrations with other capital priorities, construction of oncampus bookstacks was not a possibility for any of the institutions.

\section{Prospector Union Catalog}

Colorado academic libraries have a lengthy history of cooperative projects. In the early 1980s, for example, the Colorado Alliance of Research Libraries pioneered in creating its own online library system. ${ }^{10}$
In 1998, the Alliance, of which all four PASCAL partners are members, initiated Prospector. This shared union catalog merges the library catalogs of the major Colorado academic libraries, including all four PASCAL partners, into a single union catalog. Users can choose to search only their local catalog or can search in the Prospector union catalog and make online requests for delivery of materials held by any other Prospector library.

Prospector currently merges the catalogs of twenty-three libraries in Colorado and Wyoming and includes large public academic, medium-sized private academic, and public libraries as well as three different brands of automated library systems. Prospector participants include such large systems as the Denver Public Library, the University of Northern Colorado, and the University of Wyoming, as well as much smaller libraries such as the Fort Collins Public Library, the University of Denver Law Library, and Mesa State College. More than one and a half million users are registered in Prospector. ${ }^{11}$

The Prospector union catalog provided a key piece of automation in the implementation of cooperative collection management at PASCAL. As materials were moved to PASCAL, database records would be updated on both the local system and the Prospector system. Any user searching the Prospector catalog could see PASCAL holdings, regardless of the library that submitted and owned the item. This capability drove much of the philosophy and many of the policy decisions pertaining to collection management of stored materials.

\section{Shared Collection Management}

A governing board composed of the four library deans and directors of the four institutions was established to oversee construction, develop policy, hire key personnel, and monitor ongoing opera- 
tions. The governing board articulated the vision of PASCAL as a collaborative facility efficiently storing the low-use materials of the four partners, but also making those collections readily available to a statewide user base. This would include not storing duplicates, circulating all materials submitted to PASCAL, making holdings viewable through the statewide Prospector union catalog, and allowing stored materials to be directly requested by any of Prospector's registered users in Colorado and Wyoming.

Although numerous libraries jointly share a single storage facility, the stored materials are typically viewed as separate collections with each library having proprietary rights to the items it has stored. Even though housed in the same facility, the materials have been selected using criteria unique to the owning library and circulate with policies distinct to the owning library. Because most libraries move materials off-site based on some criteria of low use, there is a high likelihood of each library independently selecting the same items for off-site storage. Most significantly, however, patrons may have little or no access to stored collections that their library does not distinctively own.

In contrast, having an online union catalog through which all participants and their patrons could readily view each other's holdings presented an opportunity for the four PASCAL partners. It was recognized that if all PASCAL holdings were reflected in Prospector, it could serve as a resource through which the stored collections could be managed collaboratively and made available directly to the broader Prospector constituency. However, controversial issues such as continuing ownership, access policies, joint retention decisions, and retention had to be resolved as construction was under way.

\section{Continuing Ownership and Access}

When discussion of the concept of a jointly occupied high-density storage facility that incorporated collaboratively managed collections began in 1999, several concerns were raised concerning its operation. Perhaps the issue of most concern to librarians was ownership of stored materials. There was a widespread perception among collection managers at the four institutions that jointly owned, off-site materials could not be considered part of the local collections. Accreditation standards, correctly or not, were most often cited as the impediment to moving large collections off-site. Upon investigation, however, no accrediting body required library materials to be on campus for them to be counted as part of the collection. But holdings counts were important for various statistical reporting. This was complicated by the variety of bodies to which the PASCAL partners reported.

Effective resource sharing, however, depends on seamless access to materials. A key policy decision agreed to by the PASCAL partners provided for local ownership, but also for universal circulation of stored materials. That is, all material submitted to PASCAL would be represented through the Prospector catalog and would circulate to any of the twenty-three participating libraries. This decision proved controversial. A few collection managers felt an aversion to putting valuable collections at risk by opening their use to a much larger public. Although these collections, often uncataloged, had always been available to outside users through interlibrary loan, borrowing was a cumbersome and slow process that limited potential requestors. With its simple online request mechanism, Prospector promised rapid delivery to the patron. For those managers who had invested their careers in 
carefully selecting items for distinguished collections, even sending materials off-site was difficult and circulating them to an unknown and potentially abusive public was too much. Another concern was that by mandating circulation of all PASCAL materials, rare and archival materials would be excluded from storage. These items were noncirculating in the owning library and, because they could not realistically ever be permitted to circulate, would be inappropriate for PASCAL. But with its state-of-the-art environmental controls, PASCAL was particularly suited for just such materials.

In the end, it was felt that universal access outweighed the need for rare books storage and PASCAL opened with a policy of circulation for all stored materials. For the purposes of electronic searching and delivery, then, PASCAL appears to the user as any other library in the Prospector system. For example, a user anywhere in Colorado can perform a Prospector title search, find the item to be in PASCAL, and request the piece be delivered by courier. It is no different than searching any other title or requesting delivery from any other Prospector library. Loan requests made through Prospector for PASCAL materials conform to the common Prospector loan policies. This seamless integration of PASCAL holdings into the Prospector catalog has contributed to remarkable usage of the collection by non-PASCAL partners throughout Colorado. Nearly 22 percent of all PASCAL circulation was requested through Prospector by non-PASCAL partners in 2003, and usage by non-PASCAL partners is increasing rapidly. One consequence of such outside usage is that PASCAL is considering extra staffing just to retrieve such requests.

\section{Local Selection and Joint Retention Policy}

Early in the planning process, the governing board agreed that "It [is] a desirable general approach to consider PASCAL as a library of record." That is, PASCAL would hold the remaining last copy of any monograph or journal volume for all partners to share. This would free each partner from maintaining the scholarly record on-site. If the item was stored in PASCAL, the remaining partners would deaccession their copies rather than store them in PASCAL. However, this did not mean that there would be strict submission guidelines for materials submitted to PASCAL. Instead, in the same planning document, the governing board concluded that "PASCAL is for permanent storage of low-use items, which will be locally defined."

If "low use" was left for local interpretation, however, the issue of duplication of submissions was not. According to the program plan, "Only with this sort of shared facility can participating libraries make permanent, joint retention decisions to minimize duplication of stored items, especially in the area of back runs of journals. Shared use data on important but lesser used research materials can be collected in order to implement a policy of minimal storage duplication. Collaborative decisions can be made to determine which copies are retained for storage, allowing every participating library to rely on permanent retention, in a preservationorientated facility, of the copy which has been retained." 12

Although the four institutions were diverse in mission, three-CU Boulder, CU Denver, and the University of Denver-had large undergraduate populations and each library held collections to support such instruction. Consequently, it was felt there was the possibility of unnecessary duplicate materials being sent to off-site storage, particularly with large serial sets. For example, there was the likelihood that each institution would submit dozens of bound volumes of Sci- 
entific American, Time, and Encyclopedia Britannica. Such submissions could fill the storage facility with unnecessary duplicates and accelerate the need for an expensive second storage module.

Negotiating the details of a four-campus retention policy proved a challenge. Unnecessary duplication is difficult to define, and duplication to one institution may represent an important third copy to another. Some librarians were concerned that simultaneously mandating that all PASCAL materials circulate while limiting PASCAL submissions to a single copy put collections at risk. As an ARL library, the Boulder campus had as its mission to preserve the scholarly record. Circulating irreplaceable last copies, some librarians argued, compromised that charge. Deep concern also was expressed that the single-copy policy would erode local control over collection development. For example, if three libraries weeded their copies of a title based on the presence of a copy being in PASCAL, what would happen if the owning library permanently recalled that item to its shelves? The item might not be as transparently available to those libraries that weeded their copies. Such concerns prompted important compromises among the partners in negotiating the retention policy.

For monographs, it was agreed that "single copy" was to be defined as one copy for each partner. Therefore, up to four of the same monograph could be submitted to PASCAL. This was seen as an important processing concession. Otherwise, every monograph submitted to PASCAL would have to be searched in Prospector to determine whether it duplicated an existing title. With hundreds of thousands of titles moving to PASCAL, searching each title was seen as too time-consuming to be practical. By agreeing to send no more than one copy from each library, the collection manag- ers felt they could maintain the spirit of the agreement without move schedules coming to a halt. In reviewing materials for storage, for example, a collection manager confronting three shelved copies of a title could keep one on the shelf, flag one for weeding, and flag one for storage. The burden of physically moving materials through a local or Prospector search routine was avoided while minimizing potential duplication.

For serials, where a greater possibility for duplication existed among the partners, it was agreed that only a single copy would be accepted in PASCAL. Duplicates were to be identified based on OCLC number and title as well as a match on specific holding information from records in Prospector. Although duplicate volumes were not to be sent, fill-in volumes were welcomed. An entire serial set, then, may comprise volumes owned by several partners. As with monographs, each library retains ownership of the serial volumes it stores in PASCAL. Unlike monographs, serial volumes may not be returned permanently to the owning library. When a serial is moved to PASCAL, it is permanently stored in the facility. Any PASCAL partner may request a long-term loan from the governing board, regardless of ownership of the volumes. This policy is intended to address concerns that critical materials may be withdrawn unexpectedly from PASCAL. At the same time, collection managers must weigh the need for on-site shelf space against the reality of never being able to permanently return serials submitted to PASCAL.

Negotiating the monograph and serial submission polices among the PASCAL partners was a time-consuming, but critical step. Although permitting each library to submit one copy of a monograph might appear self-defeating, it was anticipated that the practice would have little impact on overall space consumption in PASCAL 
because nearly 70 percent of PASCAL contents were projected to be serial volumes. Moreover, because the mission of each of the four libraries was somewhat different, the monographic duplication among the four partners was known to be relatively small. With relatively few monographs going to PASCAL and with little monographic duplication among partners' collections, this was viewed as an acceptable compromise.

For all materials, it was agreed that only collection managers had authority to determine whether an item was a duplicate. PASCAL staff could not "return items on the grounds of perceived duplication." Identifying duplicates from libraries with histories of very different cataloging practices was not as obvious as was first thought. Boulder, for example, had a history of cataloging by unique title whereas the Health Sciences library generally cataloged by series title. This difference, as well as many more subtle differences in cataloging practice, precluded students from accurately determining whether items duplicated one another. Consequently, collection managers were given final authority to determine whether an item duplicated a PASCAL holding.

\section{Conclusion}

PASCAL combines low-use materials from four distinct institutions into a single collection directly accessible to regional users through a union catalog and circulates its holdings, regardless of institutional ownership, under a single set of loan policies. The four PASCAL partners also have pioneered a practice of coordinating submissions, including nonduplication of materials, to maximize storage space. Such collaboration has elevated PASCAL from being an isolated storage annex to becoming a regional resource similar, in many ways, to a standalone library.
Institutionalizing the single-copy concept was more complicated than the planners had envisioned and its implementation involved important compromises. Collection managers, interested in preserving the scholarly record, were concerned that circulating last copies was imprudent. Storage planners, wanting to maximize storage capacity, worried that limited space would be consumed by thousands of duplicates. Permitting a single copy of a monograph per institution, but only one serial volume for the partnership, seems to have balanced collection managers' concerns regarding redundancy with the constraints of limited storage capacity. PASCAL is filled to slightly over half its capacity; however, no quantitative assessment of duplication has been performed on the collection. There is a perception that this policy is successful in reducing or eliminating stored duplicates, but because of the decentralized nature of materials selection, it is impossible to know conclusively if the policy has been successful. An indirect measure of success would be to determine whether the number of duplicates stored in PASCAL exceeds the number the policy allows. In addition, it would be useful to examine loss rates and any instances in which materials were permanently returned to owning libraries.

Making low-use materials available to a large, nonacademic user base was viewed with some trepidation by many collection managers. They repeatedly reminded planners that "low use" does not mean irrelevant. In fact, low-use materials are often the unique research materials that most distinguish a library's collection. That collection managers would be hesitant to place such valuable material under the control of an off-site storage facility that would circulate items to any of one and a half million people is not surprising. Perhaps more surprising, though, is how 
heavily those materials are being used by external patrons. That nearly 25 percent of all PASCAL loan requests are from non-PASCAL institutions underscores the collection managers' assessment of the value of such materials. Furthermore, this suggests that, when seamlessly accessible, low-use materials at one institution may be requested routinely by another. Despite-or perhaps because of-such usage, collection managers of the four institutions continue to submit materials and PASCAL's remaining vacant storage is fully committed.

That other institutions are formally requesting to join the PASCAL partnership is evidence that the collaborative model of PASCAL has been successful. Plans for the second storage module are likely to include additional academic partners and may contain public library partners as well. At that point, PASCAL will become an integrated part of the collection management strategies of the region.

\section{Notes}

1. Martha Kyrillidou and Mark Young, ARL Statistics, 2001-2002 (Washington, D.C.: ARL, 2003), 24-29.

2. Richard J. Bazillion and Connie L. Braun, Academic Libraries as High-tech Gateways, 2 nd ed. (Chicago and London: ALA, 2001).

3. William G. Jones, "Library Buildings: Renovation and Reconfiguration," ARL SPEC Kit 244 (April 1999), 14,18.

4. ARL, Library Storage Facilities, Management, and Services, SPEC Kit 242 (Washington, D.C.: ARL, May 1999).

5. David Weeks and Ron Chepesiuk, "The Harvard Model and the Rise of Shared Storage Facilities," Resource Sharing \& Information Networks 16, no. 2 (2002): 159-68; Scott Seaman, "Highdensity Off-site Storage: Document Delivery and Academic Library Research Collections," Journal of Interlibrary Loan, Document Delivery E Information Supply 13, no. 3 (2003): 91-103; Ronald Chepesiuk, "Reaching Critical Mass: Off-site Storage in the Digital Age," American Libraries 30, no. 4 (Apr. 1999): 40-43.

6. Steve O'Connor, Andrew Wells, and Mel Collier, "A Study of Collaborative Storage of Library Resources," Library Hi Tech 20, no. 3 (2002): 258.

7. Willis E. Bridegam, A Collaborative Approach to Collection Storage: The Five-College Library Depository (Washington, D.C.: Council on Library and Information Resources, 2001), 29.

8. Paulien \& Associates, Inc., "A Program Plan for a Library Remote Storage Facility for the University of Colorado at Boulder, University of Colorado at Denver, University of Colorado Health Sciences Center, with the Participation of the University of Denver" (Apr. 1997): 23. Available online from http://ucblibraries.colorado.edu/adminservices/seaman/PASCAL.pdf ; Internet. [Accessed 9 August 2004].

9. Brice Austin and Scott Seaman, "Temporary Remote Book Storage at the University of Colorado at Boulder Libraries: Facilities Planning, Materials Preparation, Selection, and Retrieval," Collection Management 27, no. 1 (2002): 59-78.

10. Rebecca T. Lenzini and Ward Shaw, "Creating a New Definition of Library Cooperation: Past, Present, and Future Models, Library Administration E Management 5, no. 1 (1991): 37-40.

11. "Prospector: The Unified Catalog." Available online from http://prospector.coalliance. org/;Internet. [Accessed 9 August 2004].

12. Paulien \& Associates, "A Program Plan for a Library Remote Storage Facility," 6. 